\title{
Influência da Massa na Remoção de ĺons Ni(II) em Águas, Utilizando a Fibra do Coco (Cocos Nucifera L.) como Material Adsorvente
}

\author{
Lucas G. Corrêa, Danúbia O. Melo, Túlio N. Matos, \\ Cleide S. T. Araújo \& Helén C. Rezende
}

A grande quantidade de resíduos gerados na produção industrial tem causado grandes problemas ambientais. Ións metálicos como o $\mathrm{Ni}$ (II) são uma das principais causas, especialmente em meio aquoso. Portanto, é necessário buscar técnicas para sua remoção. O método de adsorção foi aplicado utilizando fibras de coco secas como material adsorvente, que é uma técnica de baixo custo e alta eficiência. Para isso, foi realizado o procedimento através do método univarido, com a massa do adsorvente como variável, para verificar sua influência na porcentagem de remoção de íons metálicos.

Palavras Chave: Adsorção; Águas; Adsorvente; Níquel; Coco.

The large amount of waste generated in industrial production has caused major environmental problems. Metal ions such as Ni(II) are one of the major drawbacks, especially in aqueous media. Therefore, it is necessary to search for techniques to remove them. The adsorption method was applied using dry coconut fibers as adsorbent material, which is a low cost and high efficiency technique. For this, the univariate method will be performed, with the mass of the adsorbent as variable. In order to verify its influence on the percentage of removal of metal ions.

Keywords: Adsorption; Waters; Adsorbent; Nickel; Coconut. 


\section{Introdução}

A água é um dos principais recursos naturais disponível aos seres vivos, está presente em $70 \%$ da superfície terrestre (PEREIRA; FREITAS, 2017). Porém com o desenvolvimento industrial associado ao crescimento populacional do planeta, diversos impactos ambientais vem afetando a disponibilidade deste bem de extrema essencialidade (GONÇALVES JÚNIOR, 2013).

Processos industriais que envolvem a utilização da água nas etapas de produção geram grandes quantidades de efluentes com vários tipos de contaminantes. Destacam-se os íons metálicos que são contaminantes preocupantes, pois possuem grande toxicidade aos seres vivos, tendo como exemplos os íons Cd (11), Ni (11) e Pb (11) (MÓDENES et al., 2013). Tais íons são bastante utilizados em várias áreas como galvanoplastia, produção de fertilizantes, mineração, metalurgia e fabricação de baterias, configurando contaminante em potencial de recursos hídricos (GOOGERDCHIAN et al., 2012).

O níquel (Ni) é um dos metais tóxicos mais comumente utilizados dá principalmente em biofontes sólidas, derivados de fertilizantes fosfatados e pesticidas, sendo sua espécie iônica Ni(1l) a mais inserida (MELLIS; CRUZ; CASAGRANDE, 2004).

Várias técnicas têm sido utilizadas para a remoção de íons metálicos em águas, tais como filtração por membrana, troca iônica, tratamento eletroquímico entre outras (XIAO et al., 2012). Porém são técnicas que envolvem alto custo, dessa forma, usa-se de métodos alternativos como a adsorção com materiais naturais que possuem, além das qualidades, uma alta eficiência no processo de remoção de íons metálicos (FERREIRA et al., 2015).

Quando trata-se do uso de materiais naturais na técnica de adsorção, os resultados apresentam maior eficiência de retenção, portanto, além do baixo custo que proporcionam, estes materiais naturais oferecem opções para seu aproveitamento, o que limita o impacto ao meio ambiente. Dentre os adsorventes naturais, aqueles não produzidos sinteticamente, podendo ser de origem mineral ou não, destacam-se os lignocelulósicos, como resíduos de soja, arroz, coco entre outros que são subprodutos agroindustriais cuja abundância e características renováveis, propiciam grande interesse no uso desses materiais (FLECK; TAVARES; EYNG, 2013).

O coqueiro (Cocos nucifera L.) é difundido naturalmente no globo terrestre, ocorrendo em praticamente todos os continentes. A facilidade de obtenção, baixo custo e alta disponibilidade são vantagens adicionais apresentadas por este tipo de material. Em virtude desta dispersão e adaptabilidade, seu cultivo e sua utilização se dão de forma expressiva, com uma gama de produtos e subprodutos, tanto na forma "in natura" quanto industrializada (MARTINS, JESUS JÚNIOR, 2011). O uso das fibras do coco como material adsorvente para íons metálicos em água está sendo bastante utilizado devido os seus diversos benefícios, além dos citados anteriormente, mostrando dessa forma que pode-se remediar ambientes aquosos contaminados com diversos íons metálicos tóxicos através de métodos simples e de baixo custo (COSTA; MENDONÇA; JUNIOR, 2017).

O objetivo do trabalho é avaliar a capacidade das fibras do coco seco (Cocos nucifera L.) para a remoção de íons $\mathrm{Ni}(11)$ em águas, verificando a influência da massa do material na adsorção, investigando materiais alternativos em processos de remediação química de ambientes aquosos contaminados com íons metálicos

\section{Metodologia}

As fibras do mesocarpo seco de Cocos nucifera L. "in natura" e sem nenhum tratamento químico foram obtidas no comércio local da cidade de Anápolis-GO, no mês de setembro de 2017. As fibras foram separadas, lavadas com água deionizada, secas em estufa com circulação de ar por um período de 48 horas à $40^{\circ} \mathrm{C}$, trituradas em moinho de facas, peneiradas em peneiras com tamanho de partículas de 100 a 115 mesh e acondicionadas em frascos de polietileno à temperatura ambiente.

Para a otimização da variável massa do adsorvente foi preparada uma solução individual do metal de interesse 10 mg.L-1 a partir de solução padrão de Ni (II), de grau analítico com concentração 1000 mg.L-1.

As vidrarias foram calibradas, limpas e colocadas em 
solução de ácido nítrico $\left(\mathrm{HNO}_{3}\right)$ a $10 \%$ por um período de 24 horas, enxaguadas com água destilada e secas à temperatura ambiente. O ajuste do $\mathrm{pH}$ das soluções foi realizado utilizando potenciômetro microprocessado com soluções de Hidróxido de sódio $\mathrm{NaOH}$ e ácido nítrico $\mathrm{HNO}_{3}$ ambas de concentração $0,3 \mathrm{~mol} \mathrm{~L}^{-1}$. O pH empregado foi o 7 .

Foi utilizado o método univariado para a otimização da variável onde os valores da massa do adsorvente variou foram 25, 50, 100, 150 e $200 \mathrm{mg}$.

As soluções contendo $15 \mathrm{~mL}$ de $\mathrm{Ni}(11)$ foram agitadas com a respectiva massa de adsorvente e tempo determinado de 20 minutos, à temperatura ambiente, em frascos de polietileno e agitador magnético. Após a agitação as soluções foram filtradas em sistema de filtração simples, utilizando papel de filtro Quanty. Com o sobrenadante foi feita uma análise por Espectroscopia de Absorção Atômica com Chama (FAAS), para a quantificação de íons Ni(11).

\section{Resultados e Discussão}

Para a mesma concentração de íons Ni(11), foi realizado o estudo da adsorção em relação a massa das fibras de coco trituradas. As quantidades de massa utilizada para tal variaram de 25 a $200 \mathrm{mg}$ como mostra a tabela 1.

Tabela 1. Estudo da variação da massa do adsorvente na remoção de íons Ni(11) em água.

\begin{tabular}{|c|c|c|c|}
\hline $\begin{array}{c}\text { Massa do } \\
\text { adsorvente } \\
(\mathrm{mg})\end{array}$ & Absorbância & Padrão & \% de remoção \\
\hline 25 & 0,219 & 0,437 & 49,81 \\
\hline 50 & 0,196 & 0,437 & 55,15 \\
\hline 100 & 0,196 & 0,437 & 55,15 \\
\hline 150 & 0,196 & 0,437 & 55,15 \\
\hline 200 & 0,177 & 0,437 & 59,57 \\
\hline
\end{tabular}

Os resultados mostraram que para massas maiores do adsorvente, a porcentagem de remoção de íons $\mathrm{Ni}(11)$ foi maior, porém em um valor pouco significativo de diferença. Entre os valores de massa de 50 a $150 \mathrm{mg}$ a quantidade removida foi a mesma, mostrando a possibilidade de equilíbrio do sistema.

Diante destes resultados pode-se considerar que a massa ótima do sistema é de $25 \mathrm{mg}$, uma vez que ao utilizar quantidades menores do material, garantirá um custo menor no procedimento, além de reduzir o impacto ambiental gerado pelo resíduo.

\section{Conclusões}

$\mathrm{O}$ estudo da influência da massa do adsorvente é necessário, visto que sua utilização gera custos e resíduos. Portanto, conhecer a quantidade mínima de adsorvente que remova boa quantidade de íons $\mathrm{Ni}(11)$ em águas é essencial, pois definido tal valor é possível avaliar a Capacidade Máxima de Adsorção (CMA) do material.

\section{Agradecimentos}

Ao Programa Institucional de Bolsas de Iniciação Científica (PIBIC) CNPq. Ao programa de concessão de Bolsa de Incentivo ao Pesquisador (BIP), instituído pela lei estadual n. 18332/2013.

\section{Referências Bibliográficas}

1. Costa, D. A.; Mendonça, R. H.; Junior, M. M. W. Avaliação da remoção de cromo (III) por materiais compósitos porosos adsorventes de PE-g-MA, fibra de coco e quitosana, usando planejamento experimental. Engenharia Sanitaria e Ambiental, p. $1-11,2017$.

2. Ferreira, P. P. L. et al. Adsorção de $\mathrm{Cu} 2+$ e $\mathrm{Cr} 3+$ em efluentes líquidos utilizando a cinza do bagaço da cana-de-açúcar. Ceramica, v. 61, p. 435-441, 2015.

3. Fleck, L.; Tavares, M. H. F.; Eyng, E. Adsorventes naturais como controladores de poluentes aquáticos : uma revisão. Revista EIXO, v. 2, n. 1, p. 39-52, 2013.

4. Gonçalves Júnior, A. C. Descontaminação e monitoramento de águas e solos na região amozônica utilizando materiais adsorventes alternativos, visando a remoção de metais pesados tóxicos e pesticidas. Inc. Soc., Brasília, v.6, p. 105-113, 2013.

5. Googerdchian, F., Moheb, A., Emadi, R. Lead sorption properties of nanohydroxyapatite-alginate composite adsorbents. Chemical 


\section{Artigo Geral 19}

Engineering Journal, v. 200-202, p. 471-479, 2012.

6. Mellis, E. V.; Cruz, M. C. P. Da; Casagrande, J. C. Nickel adsorption by soils in relation to $\mathrm{pH}$, organic matter, and iron oxides. Scientia Agricola, v. 61, n. 2, p. 190-195, 2004.

7. Módenes, A. N. et al. Removal of heavy metals Cd (II), Cu (II) and $\mathrm{Zn}$ (II) biosorption process by using the macrophyte Eicchornia crassipes. Rem: Revista Escola de Minas, v. 66, n. 3, p. 335-362, 2013.

8. Pereira, J. C.; Freitas, M. R. Cities and Water Security in the Anthropocene: Research Challenges and Opportunities for International Relations. Contexto Internacional, v. 39, n. 3, p. 521-544, dez. 2017.

9. Xiao, Z.H. et al. Magnetically recoverable Ni carbon nanocomposities: Solid- state synthesis and the application as excellent adsorbents for heavy metal ions. Applied Surface Science, v. 263, p. 795-803, 2012.

\section{Lucas G. Corrêa ${ }^{*}$, Danúbia O. Melo', Túlio N. Matos', Cleide S. T. Araújo² \& Helén C. Rezende ${ }^{2}$}

${ }^{1}$ Universidade Estadual de Goiás - Campus de Ciências Exatas e Tecnológicas Henrique Santillo/CCET

${ }^{2}$ Universidade Federal de Goiás - Regional de Jataí

E-mail: lucasgomes7.correa@hotmail.com 